\title{
Защита отечественной селекции и семеноводства овощных культур- главная задача АНРСК
}

\section{Protection of national plant breeding and vegetable crops seed production is the main task of AlRSC}

Леунов В.И., Коноваленко И.М.

\section{Аннотация}

Ассоциация независимых российских семенных компаний (АНРСК) занимает активную позицию при отстаивании интересов своих членов и отрасли в целом. При защите интересов участников Ассоциации постепенно продвигается идея создания более эффективного, конкурентоспособного и цивилизованного рынка семян овощных культур и любительского рынка цветочных и декоративных растений. АНРСК координирует свою деятельность с общественными объединениями. Она объединяет более 20 организаций, которые обеспечивают производство и реализацию семян овощных, бахчевых и цветочных культур для профессионального и любительского рынков в объеме 70-90\% от их общей потребности в России. В статье показано значение Ассоциации для развития отечественной селекции и семеноводства овощных культур. В течение 2019 года Советом директоров Ассоциации подготовлены и направлены обращения в такие органы, как: ЕЭК, Госдума ФС РФ, Минсельхоз РФ, Правительство РФ, ФС Россельхознадзор, Федеральная антимонопольная служба РФ, Совет Федерации ФС РФ. В настоящее время продолжается работа по реализации механизма «регуляторной гильотины». Представитель Ассоциации вошел в одну из экспертных групп и теперь на постоянной основе принимает участие в заседаниях и доводит до разработчиков позицию членов нашей Ассоциации. Совет директоров и Секретариат AHPCK в соответствии с решениями Общего собрания AHPCK и решениями Совета директоров в отчетном 2019 году постоянно проводили комплекс мероприятий по превращению отечественного семеноводства в современную отрасль, развивающуюся на новейших технологиях в условиях современных рыночных отношений. Ассоциация концентрирует усилия по решению вопросов, связанных с созданием новых современных условий для развития селекции и семеноводства овощных культур, и, прежде всего, по государственному субсидированию селекционных программ в овощеводстве, независимо от форм собственности селекционных организаций, расширению научных исследований по разработке новых селекционных методик, параметров технологических приемов, оптимизации налоговой политики в селекции и семеноводстве, льготного кредитования в этой сфере и т. д.

Ключевые слова: ассоциация, семена, селекция, семеноводство овощных культур, приказ, проект, требования, федеральный закон, контроль, надзор, «регуляторная гильотина».

Для цитирования: Леунов В.И., Коноваленко И.М. Защита отечественной селекции и семеноводства овощных культур главная задача АНРСК // Картофель и овощи. 2020. №2. С. 3-8. https://doi.org/10.25630/PAV.2020.18.2.001
Leunov V.I., Konovalenko I.M.

Abstract

The Association of Independent Russian Seed Companies (AIRSC) takes an active position in defending the interests of its members and the industry as a whole. While protecting the interests of the Association members, the idea of creating a more efficient, competitive and civilized market for vegetable seeds and an amateur market for flower and ornamental plants are gradually moving forward. AIRSC coordinates its activities with public associations. It unites more than 20 organizations that provide for the production and sale of seeds of vegetable, melon and flower crops for professional and amateur markets in the amount of 70 $90 \%$ of their total demand in Russia. The article shows the importance of the Association for the development of domestic selection and seed production of vegetable crops. During 2019, the Board of Directors of the Association prepared and sent appeals to such bodies as: EEC, State Duma of the Federal Assembly of the Russian Federation, Ministry of Agriculture of the Russian Federation, Government of the Russian Federation, FS Russian agricultural supervision, Federal Antimonopoly Service of the Russian Federation, Federation Council of the Federal Assembly of the Russian Federation. Currently, work continues on the implementation of the so called regulatory guillotine mechanism. The representative of the Association entered one of the expert groups and now takes part in meetings on an ongoing basis and brings to the developers the position of members of our Association. The Board of Directors and the Secretariat of AIRSC in accordance with the decisions of the General Meeting of AIRSC and the Decisions of the Board of Directors in the reporting 2019 constantly carried out a set of measures to turn domestic seed production into a modern industry that is developing on the latest technologies in modern market relations. The Association concentrates its efforts on issues related to the creation of new modern conditions for the development of selection and seed production of vegetable crops, and above all, on state subsidies for selection programs in vegetable production, regardless of the forms of ownership of selection organizations, expansion of scientific research on the development of new selection methods, parameters of technological techniques, optimization of tax policy in selection and seed production, preferential lending in this area, etc.

Key words: association, seeds, selection, vegetable seed production, order, draft, requirements, federal law, control, supervision, regulatory guillotine.

For citing: Leunov V.I., Konovalenko I.M. Protection of national plant breeding and vegetable crops seed production - the main task of AIRSC. Potato and Vegetables. 2020. No2. Pp. 3-8. (In Russ.). https://doi.org/10.25630/PAV.2020.18.2.001
A ссоциация занимает активную позицию при отстаивании интересов своих членов и отрасли в целом. Прошедшие 20182019 годы оказались очень важными с точки зрения новых законодательных инициатив в сфере регулирования отечественных селекции и се- меноводства и плодотворными на введение новых административных барьеров.

При защите интересов участников Ассоциации постепенно продвигается идея создания более эффективного, конкурентоспособного и цивилизованного рынка семян овощ- ных культур, а также любительского рынка цветочных и декоративных растений.

При этом удается грамотно формировать свою позицию, и аргументировано убеждать оппонентов во взаимной выгоде от принимаемых решений. Уже сейчас 
AHPCK - ассоциированный член ISF (Международной Федерации по семенам) и Торгово-промышленной Палаты РФ. Ассоциация продолжает развивать прочные деловые связи с другими некоммерческими организациями, защищающими права предпринимателей, так как именно успехи бизнеса - движущая сила для развития экономики нашего государства.

АНРСК координирует свою деятельность с таким общественными объединениями и структурами, как Общероссийская общественная организация малого и среднего предпринимательства «Опора России», Российский союз промышленников и предпринимателей, Ассоциация компаний оптовой и розничной торговли, Торгово-промышленная палата РФ, Российский зерновой союз, Ассоциация производителей посадочного материала, Картофельный союз и др.

Компании-члены АНРСК - коллективные члены Российской академии естественных наук, участники APSA (Ассоциации семенных компаний Азиатско-Тихоокеанского региона), ASTA (Американской семеноводческой торговой ассоциации).

Ассоциация активно

трудничает С Евразийской Эко номической Комиссией (ЕЭК), Минэкономразвития РФ и Федеральной антимонопольной службой России (ФАС), проводит активную работу на площадках МинсельхозаРФ, Россельхознадзора и Аналитического центра Правительства РФ.

Сегодня Ассоциация объединяет более 20 организаций, которые обеспечивают производство и реализацию семян овощных, бахчевых и цветочных культур для профессионального и любительского рынков в объеме 70-90\% от их общей потребности в России. В состав АНРСК входят частные селекционно-семеноводческие фирмы (как российские, так и зарубежные), а также государственные научные учреждения. При этом деятельность Ассоциации направлена на решение спектра самых различных проблем, связанных с ущемлением прав и законных интересов хозяйствующих субъектов. Среди них можно выделить следующие: вопросы, связанные с работой селекционных учреждений, развитие элитного семеноводства, доработка семян, реализация конечной продукции.
Представители Ассоциации входят в экспертную рабочую группу, созданную во исполнение поручения Президента РФ, по внесению изменений в законодательство РФ, предусматривающих отмену с 01.01.2021 всех нормативных правовых актов, устанавливающих требования, соблюдение которых подлежит проверке при проведении государственного контроля (надзора), и введение в действие новых норм, содержащих актуализированные требования, разработанные с учетом рискоориентированного подхода и современного уровня технологического развития в соответствующих сферах («регуляторная гильотина») и по административному реформированию управления селекцией и семеноводством.

Цель: анализ работы Ассоциации за прошедший календарный год, в том числе ее значение для развития отечественной селекции и семеноводства овощных культур [1, 2].

Условия, материалы и методы исследований

При анализе использовали абстрактно-логический метод, включающий совокупность приемов индукции и дедукции, анализа и синтеза, аналогии, сопоставлений, системно-структурный анализ, методы формализации, моделирования, прогнозирования.

\section{Результаты исследований}

Экономика страны в условияхсанкций, можно сказать, перерождается заново, и это влечет неизбежность издержек. Члены АНРСК, например, чувствуют усиливающееся административное давление, непредсказуемость и нормативную неурегулированность в сфере отечественной селекции и семеноводства.

Достаточно привести в пример хотя бы октябрьский проект федерального закона «О семеноводстве», подготовленный специалистами Россельхознадзора [3]. Указанный проект не только сохраняет все недостатки предыдущей версии, но и предлагает ввести 26 новых функций и полномочий, характерных для надзорного органа.

Немало хлопот доставило правоприменение Россельхознадзором норм Постановления Правительства РФ № 128. В частности, оно необоснованно осложнило ввоз в РФ любых партий семян, обязав отечественных предпринимателей выполнять не только Единые карантинные фитосанитарные требования, установленные правом ЕАЭС, но и требо- вания Постановления Правительства № 128, которые не распространяются на предпринимателей из других государств-членов ЕАЭС.

Для решения этой проблемы в течение 2019 года Советом директоров Ассоциации подготовлено и направлено девять обращений в такие органы как:

- ЕЭК (в марте и ноябре);

- Государственная Дума ФС РФ (в августе);

- Минэкономразвития РФ (в августе);

- Минсельхоз РФ (в августе);

- Правительство РФ (в августе);

- ФС Россельхознадзор (в августе);

- ФАС (в августе);

- Совет Федерации ФС РФ (в ноябре).

Темнеменее, решитьпроблемуне удавалось, пока этот вопрос не прозвучал на встрече представителей немецкого бизнеса с Президентом РФ в Сочи. В настоящее время руководителю Россельхознадзора поставлена задача непосредственно заняться решением этой проблемы.

Немаловажной проблемой, стоявшей перед дирекцией, было правоприменение Россельхознадзором Приказа № 622 Минсельхоза РФ. Для этого было подготовлено и направлено пять обращений. В частности, в Минсельхоз РФ (в январе, феврале и апреле), в ФСБ (в апреле) и в ФАС (в марте). В настоящее время этот приказ, согласно плану Минсельхоза РФ, включен в перечень нормативных правовых актов, которые будут отменены с 01.01.2021 года, вместо этого приказа будет предложен новый, который должен будет пройти общественное обсуждение.

Кроме этого Совет директоров нашей Ассоциации вынужден был заниматься очередным проектом Постановления Правительства РФ, который был подготовлен Россельхознадзором в феврале и ноябре 2019 года. Он называется «Об установлении порядка проведения государственного карантинного фитосанитарного контроля». Россельхознадзор планирует получить этим проектом новые функции по проведению проверок в сфере карантина растений и новые полномочия, которые не предусмотрены федеральным законом 206-ФЗ.

В связи с этим, Советом директоров Ассоциации подготовлены и направлены предложения в Министерство экономического развития РФ, Министерство юстиции РФ, Министерство сельского хо- 
зяйства РФ, в Российский союз промышленников и предпринимателей (РСПП) и в Торгово-промышленную палату (ТПП) РФ.

В настоящее время проект Постановления Правительства проходит антикоррупционную экспертизу в Департаменте ОРВ Минэкономразвития РФ.

Кроме того, по поручению Совета директоров Ассоциации, дирекция проводила работу по решению проблемы множественного отбора образцов семян при их ввозе на территорию РФ (ВНИИКР, март), проблемы внесения изменений в Приказ МСХ РФ № 293 (Минэкономразвития РФ, декабрь), по правоприменению норм о контроле ввозимых партий семян на содержание ГМО (прокуратура РФ, март), по проблеме оформления выписок из государственного реестра селекционных достижений, допущенных к использованию (ФГБУ Госсорткомиссия, май), по проблеме незаконного существования ФГБУ Госсорткомиссия (ФГБУ Госсорткомиссия, июнь; МСХ РФ, июль), по проблеме внесения изменений в Приказ МПС № 36, устанавливающий порядок перевозки подкарантинной продукции (Минэкономразвития РФ, август).

В рамках работы с ЕЭК дирекция подготовила и направила в июне 2019 года предложения в изменение Единых карантинных фитосанитарных требований и Единых карантинных фитосанитарных мер, а также приняла участие в обсуждении и направила свои предложения в проект решения комиссии об утверждении единых документов полевой апробации и методов сортового и семенного контроля семенных посевов (ЕЭК, октябрь) [4].

Проводилась также работа, направленная на разрушении монополии Россельхознадзора на рынке оказания услуг по карантинному фитосанитарному обеззараживанию и услуг по лабораторному исследованию образцов подкарантинной продукции на наличие карантинных вредных организмов. Сегодня эта работа во взаимодействии с ФАС продолжается, независимые аккредитованные лаборатории и лицензированные организации уже появились, но пока не могут свободно работать из-за воспрепятствования со стороны Россельхознадзора.

Оживленную дискуссию вызвал проект ФЗ о внесении изменений в ФЗ «О карантине растений» (ФАС, Минэкономразвития, сен- тябрь). Дирекция собрала предложения участников Ассоциации и направила их в ФАС и Департамент ОРВ, Минэкономразвития России $[5,6,7]$. В частности, разработчик предлагал уполномочить его на разработку, утверждение и контроль исполнения Методик проведения карантинного фитосанитарного обеззараживания (ст. 1, п. 2 Законопроекта). Это предложение нарушает принцип разделения властей (ст. 10 Конституции) и с учетом того, что Россельхознадзор сам оказывает платные услуги по карантинному обеззараживанию и по лабораторным исследованиям, то создаются условия для утверждения методик, способствующих недобросовестной конкуренции путем дискредитации всех организаций, за исключением подведомственных.

Также разработчик предлагал установить трехлетний период контроля за посевами семян, ввезенных на территорию РФ (ст. 1, п. 4, п.п. «а» Законопроекта), уполномочить Россельхознадзор быть и инициатором, и органом, принимающим решение о введении и об отмене временных ограничений на ввоз (ст. 1, п. 5, п.п. «а» Законопроекта), установить монополию Россельхознадзора на проведение карантинного фитосанитарного обеззараживания (ст. 1, п. 7 Законопроекта). Но самое важное, что разработчиком предлагается (ст. 1, п. 10 Законопроекта) установить право выполнять Россельхознадзором государственные функции по карантинному фитосанитарному контролю при ввозе за плату не до 1 января 2021 года (часть 5, ст. 34 федерального закона 206ФЗ), а на постоянной основе.

В своем обращении в ФАС мы указали, что это предложение не может быть поддержано, так как противоречит позиции Конституционного суда РФ, указавшего, что любые действия в рамках проведения государственного контроля (надзора) не могут проводиться за счет подконтрольных лиц. И, кроме этого, прямо запрещено п. 8, ст. 3 федерального закона 294ФЗ от 26.12.2008.

В настоящее время продолжается работа по реализации механизма «регуляторной гильотины». Представитель АНРСК вошел в одну из экспертных групп, и теперь на постоянной основе принимает участие в заседаниях, где и доводит до разработчиков позицию членов нашей Ассоциации.
Предложения по реализации механизма «регуляторной гильотины» были сформулированы и направлены в сентябре в Россельхознадзор, Правительство РФ, Минсельхоз РФ и РСПП, а в октябре в ТПП РФ [8, 9, 10, 11].

Совет директоров и Секретариат AНPCK в соответствии с решениями Общего собрания AНPCK и решениями Совета директоров в отчетном 2019 году постоянно проводили мероприятя по превращению отечественного семеноводства в современную отрасль, развивающуюся на новейших технологиях в условиях современных рыночных отношений. Мы стремились к формированию в России современной законодательной базы семеноводства с.х. растений, прежде всего, овощных, цветочных, декоративных и газонных трав, а также цивилизованного рынка семян овощных культур и интеграции селекционных достижений в мировую семенную индустрию.

Несмотря на то скромное место, которое занимает наша Ассоциация в ряду организаций, принимающих участие в оценке регулирующего воздействия нормативно-правовых актов Минсельхоза РФ, а также, несмотря на то, что Минсельхозу РФ иногда удается игнорировать наше существование и уклонятся от необходимых экспертных встреч, некоторых успехов нам все-таки удалось достичь.

С целью формирования благоприятного нормативного регулирования в сфере сельского хозяйства представители нашей Ассоциации приняли участие в оценке регулирующего воздействия некоторых проектов Минсельхоза России, Правительства РФ и ФС РСН на портале Министерства экономического развития РФ - www.regulation.gov. ru. В результате нам удалось отклонить утверждение Постановления Правительства РФ «Об утверждении Положения о государственном надзоре в области семеноводства в отношении семян сельскохозяйственных растений» по следующим причинам:

- в соответствии с нормами ст. 71 и ст. 72 Конституции России, семеноводство с. - х. растений не входит ни в сферу ведения РФ, ни в сферу совместного ведения РФ и ее Субъектов;

- в соответствии с нормой ст. 37.1 федерального закона 149-Ф3 «О семеноводстве» Государственный надзор в области семеноводства не яв- 
ляется самостоятельным видом надзора и происходит только при федеральном государственном лесном надзоре (лесной охране) и государственном надзоре в области сельского хозяйства;

- проект Постановления предусматривает проведение контрольнонадзорных мероприятий в отношении семян с.- х. растений (согласно названию проекта), что невозможно. Семена - не субъект права и не могут совершать противоправных действий. Нормой п. 6, ч. 5, ст. 2 федерального закона 294-Ф3 установлено, что мероприятия по контролю (надзору) проводятся только в отношении юридических лиц и индивидуальных предпринимателей, но не семян;

- нормой п. 2 и п.п. «а», п. 7 проекта Постановления установлены действия контрольно-надзорного органа в отношении нарушителей «требований» в области семеноводства семян c.- х. растений. Это противоречит п. 1, ст. 2 федерального закона 294Ф3, которым подобные действия допускаются исключительно в отношении «обязательных требований». Т.е. не любых, а только обязательных. В настоящее время обязательных требований к семенам законодательством РФ не предусмотрено;

- нормой п. 10 проекта Постановления предусмотрен осмотр семян с.- х. растений, отбор образцов и проведение лабораторных исследований и экспертизы. Подобные действия незаконны, так как результаты лабораторных исследований или экспертизы будут характеризовать семена по отношению к какому-либо стандарту, а в соответствии со ст. 28 федерального закона 149-Ф3 подтверждение соответствия семян любому стандарту проводится в соответствии с положениями ст. 21 федерального закона 184-ФЗ, т.е. добровольно;

- проект Постановления противоречит п. 2 Постановления Правительства РФ от 30 июня 2004 года № 328 и п. 2 Постановления Правительства РФ от 24 марта 2006 года № 164, в которых полномочия ФОИВ по организации проведения сортового и семенного контроля в отношении посевов и семян с.х. растений признаны избыточными и подлежащими упразднению.

\section{Выводы}

Таким образом, необходимо продолжение активной работы в сфере законодательно-нормативной регламентации семеноводства и, кро-
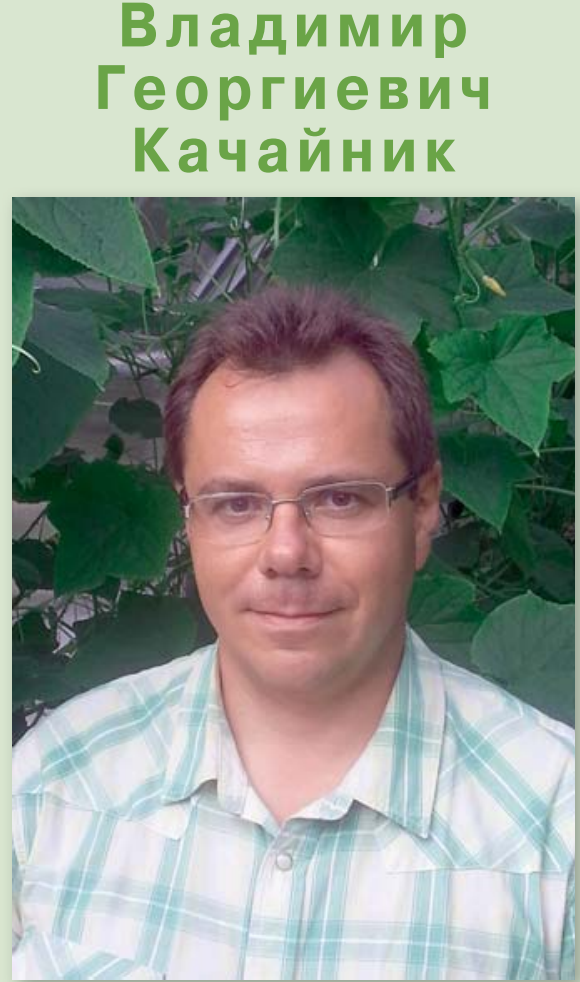

Исполнилось 50 лет Владимиру Георгиевичу Качайнику. Свой юбилей он встречает в рассвете сил, пол-

ме того, организационной структуры отрасли. Дальнейшая работа АНРСК будет сконцентрирована на разработке предложений по созданию условий привлечения в Ассоциацию других участников рынка семян, развитии сотрудничества с международными организациями (ISF, ИСТА, UPOV, OECD), семеноводческими ассоциациями развитых стран с целью дальнейшей унификации национального законодательства семеноводства, формирования взаимовыгодных экономических и научных связей.

В составе Ассоциации представлены далеко не все участники рынка семян, еще многие индивидуальные селекционеры, компании, ассоциации и союзы страны не входят в ее состав, но это не значит, что деятельность Ассоциации сконцентрирована на проблемах только своих членов. Сегодня она по существу представляет интересы всего сообщества семеноводов. У каждого из них возникают такие же проблемы и многочисленные вопросы, и мы уверены, что только совместными усилиями мы можем сделать сферу селекции и семеноводства благоприятной для успешной деятельности. ным творческой энергии и здорового жизненного оптимизма. В сравнительно молодом возрасте Владимир Георгиевич уже многое сделал для отечественного овощеводства. Им создана одна из крупнейших российских семенных компаний по овощным культурам - ООО «Агрофирма «Аэлита», которую он возглавляет и сегодня. Его активная жизненная позиция, преданность своему делу, стремление принести реальную пользу стране вызывают уважение. Он уделяет много внимания не только развитию своей компании, но и всей отрасли семеноводства, а его хорошее знание мировой семенной индустрии позволяет делать это грамотно и профессионально. Владимир Георгиевич принимает активное участие в работе Ассоциации независимых российских семенных компаний (АНРСК), причем делает это, как и все остальное, успешно, активно и искренне стремится добиться конкретных результатов в повышении конкурентоспособности отрасли.

Совет директоров АНРСК от лица всех членов Ассоциации искренне поздравляет Владимира Георгиевича с юбилеем, желает ему крепкого здоровья, счастья, дальнейших творческих успехов.

В будущем Ассоциации предстоит сконцентрировать усилия на решении вопросов, связанных с созданием новых современных условий для развития селекции и семеноводства овощных культур, и, прежде всего, по государственному субсидированию селекционных программ в овощеводстве, независимо от форм собственности селекционных организаций, расширению научных исследований по разработке новых селекционных методик, параметров технологических приемов, оптимизации налоговой политики в селекции и семеноводстве, льготного кредитования в этой сфере, обеспечении дальнейшего совершенствования нормативно-правовой базы селекции и семеноводства, устранении административных барьеров и ряде других вопросов.

АНРСК готова к сотрудничеству со всеми государственными организациями. У нее есть понимание необходимых действий для развития семеноводства и для восстановления производства семян в нашей стране. Она более других заинтересована в возможности выращивать для себя качественные семена именно в России. 


\section{Библиографический список}

1.Перечень поручений по реализации Послания Президента РФ Федеральному Собранию от 20 февраля 2019 года [Электронный ресурc] URL: http://www.kremlin.ru/acts/ assignments/orders/59898. Дата обращения: 05.11.19.

2.План мероприятий («Дорожная карта») по реализации механизма «Регуляторной гильотины», утвержденный Председателем Правительства РФ Д.Медведевым от 29 мая 2019 г. N 4714п-П36 [Электронный ресурс] URL: http://www. consultant.ru/document/cons_doc_LAW_329301. Дата обращения: 05.11.19.

3.Проект Федерального Закона «О Семеноводстве», подготовленный Россельхознадзором в ноябре 2019 года [Электронный ресурc] URL: https://rosselhoscenter.com/index. php/stati-30/19914-proekt-fz-o-semenovodstve. Дата обращения: 05.11.19.

4.Решение Совета ЕЭК от 30.11.2016 №157 «Об утверждении ЕКФТ, предъявляемых к подкарантинной продукции и подкарантинным объектам на таможенной границе и таможенной территории EAЭС» [Электронный ресурс] URL: https://www.alta. ru/tamdoc/16sr0157. Дата обращения: 05.11.19.

5.Постановление Правительства РФ от 08.02.2018 № 128 «Об утверждении Правил осуществления контроля в местах производства (в том числе переработки), отгрузки подкарантинной продукции, предназначенной для ввоза в Российскую Федерацию из иностранных государств или групп иностранных государств, где выявлено распространение карантинных объектов, характерных для такой подкарантинной продукции, в соответствии с международными договорами Российской Федерации, в целях ее использования для посевов и посадок» [Электронный ресурc] URL: http://www.consultant.ru/document/ cons doc LAW 290593. Дата обращения: 05.11.19.

6.Приказ Минсельхоза России от 12.12.2017 №622 «Об утверждении Порядка реализации и транспортировки партий семян сельскохозяйственных растений» [Электронный ресурс] URL: https://www.garant.ru/products/ipo/prime/doc/71835386. Дата обращения: 05.11.19.

7.Проект постановления Правительства РФ «Об утверждении Положения об осуществлении государственного карантинного фитосанитарного контроля (надзора)», ID: 02/07/0418/00080016 [Электронный ресурс] URL: http://orv.gov.ru/ Content/Item?n=28741. Дата обращения: 05.11.19.

8.Приказ Минсельхоза России от 13.07.2016 №293 «Об утверждении порядка выдачи фитосанитарного сертификата, реэкспортного фитосанитарного сертификата, карантинного сертификата» [Электронный ресурc] URL: https://legalacts.ru/doc/prikazminselkhoza-rossii-ot-13072016-n-293. Дата обращения: 05.11.19.

9.Приказ Министерства путей сообщения от 18.06.2003 №36 «Об утверждении Правил перевозок железнодорожным транспортом подкарантинных грузов» [Электронный ресурc] URL: https://base.garant.ru/186009. Дата обращения: 05.11.19.

10.Проект ФЗ о внесении изменений в Ф3 «О карантине растений» [Электронный ресурс] URL: http://docs.cntd.ru/ document/556175644. Дата обращения: 05.11.19.

11.Проект Решения Комиссии ЕЭК «Об утверждении единых документов полевой апробации и методов сортового и семенного контроля семенных посевов» [Электронный ресурc] URL: https:// www.alta.ru/tamdoc/19r00198. Дата обращения: 05.11.19.

\section{References}

1.List of instructions for the implementation of the Address of the President of the Russian Federation to the Federal Assembly of February 20, 2019 [Web resource] URL: http://www.kremlin.ru/ acts/assignments/orders/59898. Date of access: 05.11.19 (In Russ.).

2.Action plan («Road map») for the implementation of the "Regulatory guillotine» mechanism, approved by the Prime Minister of the Russian Federation Dmitry Medvedev on may 29, 2019 N 4714p-P36 [Web resource] URL: http://www.consultant.ru/ document/cons_doc_LAW_329301. Date of access: 05.11.19 (In Russ.).

3.Draft Federal law "On seed Production» prepared by the Rosselkhoznadzor in November 2019 [Web resource] URL: https:// rosselhoscenter.com/index.php/stati-30/19914-proekt-fz-osemenovodstve. Date of access: 05.11.19 (In Russ.).

4.Decision of the EEC Council of 30.11.2016 No. 157 «On approval of the ECFT requirements for quarantined products and quarantined objects at the customs border and customs territory of the EAEU» [Web resource] URL: https://www.alta.ru/tamdoc/16sr0157. Date of access: 05.11.19 (In Russ.).

5.Resolution Of the government of the Russian Federation of 08.02.2018 No. 128 «On approval of the Rules of control in places of production (including processing), shipment of quarantined products intended for import to the Russian Federation from foreign States or groups of foreign States, where the spread of quarantine objects characteristic of such quarantined products, in accordance with international agreements of the Russian Federation, for the purpose of its use for crops and plantings" [Web resource] URL: http://www.consultant.ru/document/cons_doc_LAW_290593. Date of access: 05.11.19 (In Russ.)

6.Order of the Ministry of agriculture of the Russian Federation No. 622 dated 12.12.2017 «On approval of the Procedure for the sale and transportation of batches of seeds of agricultural plants" [Web resource] URL: https://www.garant.ru/products/ipo/prime/ doc/71835386. Date of access: 05.11.19.

7.Draft resolution of the government of the Russian Federation "On approval of the Regulations on the implementation of state quarantine phytosanitary control (supervision)", ID: 02/07/0418/00080016 [Web resource] URL: http://orv.gov.ru/Content/ Item?n=28741. Date of access: 05.11.19 (In Russ.).

8.Order of the Ministry of agriculture of Russia dated 13.07.2016 No. 293 «On approval of the procedure for issuing a phytosanitary certificate, re-export phytosanitary certificate, quarantine certificate» [Web resource] URL: https://legalacts.ru/doc/prikazminselkhoza-rossii-ot-13072016-n-293. Date of access: 05.11.19 (In Russ.).

9.Order of the Ministry of Railways of 18.06 .2003 No 36 "On approval of the rules for transportation of quarantined goods by rail» [Web resource] URL: https://base.garant.ru/186009. Date of access: 05.11.19 (In Russ.).

10.Draft Federal law on amendments to the Federal law «On plant quarantine» [Web resource] URL: http://docs.cntd.ru/ document/556175644. Date of access: 05.11.19 (In Russ.).

11.Draft decision of the EEC Commission "On approval of unified field testing documents and methods of varietal and seed control of seed crops» [Web resource] URL: https://www.alta.ru/ tamdoc/19r00198. Date of access: 05.11.19 (In Russ.).

\section{Об авторах}

Леунов Владимир Иванович, доктор с.-х. наук, профессор, председатель совета директоров АНРСК, и.о. декана факультета агрономии и биотехнологии, ФГБОУ ВО РГАУ - МСХА имени К.А Тимирязева. E-mail: vileunov@mail.ru

Коноваленко Иван Михайлович, исполнительный директор AHPCK. E-mail: info@anrsk.ru

\section{Author details}

Leunov V.I., D.Sci. (Agr.), prof., Chairman of the Board of Directors AIRSC, acting Dean of the faculty of agronomy and biotechnology, Russian State Agrarian University - MTAA named after K. A. Timiryazev. E-mail: vileunov@mail.ru

Konovalenko I.M., executive director AIRSC. E-mail: info@anrsk.ru 